\title{
Subtracted Restriction Fingerprinting-A Tool for Bacterial Genome Typing
}

BioTechniques 34:304-313 (February 2003)

\author{
Valeri Terletski ${ }^{1,2}$, Stefan \\ Schwarz $^{2}$, Joseph Carnwath ${ }^{2}$, \\ and Heiner Niemann ${ }^{2}$ \\ ${ }^{1}$ All Russian Research Institute \\ for Animal Genetics \& Breed- \\ ing, St. Petersburg, Russia, and \\ ${ }^{2}$ Institute for Animal Science \\ (FAL), Neustadt, Germany
}

\begin{abstract}
Reproducible, discriminative, highthroughput methods are required for the identification of bacterial strains and isolates in a clinical environment. A new molecular typing method for bacteria was developed and tested on Salmonella and E. coli species. The technique is called subtracted restriction fingerprinting and is based on double restriction enzyme digestion of genomic DNA followed by end labeling. The "detection" enzyme produces TTAA overhangs that are filled in with digoxigenated nucleotides for subsequent detection, while the "subtraction" enzyme produces GCGC overhangs that are filled in with biotinylated nucleotides that permit the removal of this subset of fragments with either streptavidin-coated magnetic particles or AffiniTip ${ }^{T M}$ streptavidin columns. The two restriction enzymes are selected to produce a fragment size profile suitable for a specific analytical system. In this demonstration of the principle of subtracted restriction fingerprinting, analysis of Salmonella enterica subsp. enterica serovar Dublin and E. coli on a $30-\mathrm{cm} 1.2 \%$ agarose gel revealed up to 50 sharp evenly spaced bands, which were sufficient for the discrimination between various isolates and substrains. The restriction enzyme combinations suitable for the analysis of Salmonella and E. coli are presented. The method requires fewer enzymat-
\end{abstract}

ic steps than amplified fragment length polymorphism, does not need the specialized DNA preparation essential for pulsed field gel electrophoresis, and has a higher reproducibility than PCR-based methods.

\section{INTRODUCTION}

Fast and reliable genome typing of pathogenic microorganisms is necessary for the identification of closely related strains, for epidemiological studies, and for the detection of genetic changes (11). Some high-throughput typing systems such as SNP analysis or microarray analysis depend on prior knowledge of sequence information, but these are not useful for the detection of new sequences that arise from the acquisition of plasmids or de novo mutation. These are also not useful for the analysis of genomes that have not yet been sequenced. In these cases, random sampling methods based on randomly primed PCR or RFLP in its various forms are necessary.

The techniques currently being used for this purpose include plasmid profiling (14), AP-PCR (25), ribotyping by hybridization of genomic DNA with ribosomic DNA (2), pulsed-field gel electrophoresis following restriction enzyme digestion $(17,23,24)$, AFLP $(5,15)$, multilocus restriction typing $(1)$, multilocus enzyme electrophoresis (18), multilocus sequence typing (7), and restriction fragment end labeling $(20,22)$.

Each of these methods has inherent limitations. Plasmid profiling is restricted to the subset of bacterial species that carry "mega" plasmids. AP-PCR is rapid but is one of the least reproducible techniques for typing. Ribotyping is reproducible, but it is labor intensive be- cause it involves the hybridization of a labeled probe, and it has limited discrimination power because fewer bands are analyzed and because it focuses on only one cluster of genes (22).

The current most widely used method for bacterial typing is pulsedfield gel electrophoresis $(12,21)$. The method is based on the digestion of bacterial genomic DNA with rare cutting restriction enzymes to produce a limited number of high molecular weight fragments that are then resolved by pulsed-field gel electrophoresis. The method has high reproducibility and high discrimination power. The major limitations are that DNA extraction and restriction enzyme digestion must be performed on bacterial cells embedded in a supportive agarose matrix to avoid shearing of the high molecular weight fragments $(3,21)$ and that pulsed-field gel electrophoresis requires specialized equipment and the time to complete an analysis is six days (4).

AFLP is a PCR-based method and generally has higher discriminatory power than pulsed-field gel electrophoresis because a larger number of fragments are analyzed $(13,26)$. In practice, the number of fragments is controlled by the choice of nucleotides at the $3^{\prime}$ ends of the primer(s) used. Disadvantages common to this and other PCR-based techniques include the high cost of multiple analyses and an interassay reproducibility that is reported to be as low as $90 \%(6,22)$.

Restriction fragment end labeling is the method with the greatest potential for genomic typing. It gives high discriminatory power and reproducibility $(3,8)$, and its uniform band intensity permits automated computer analysis. The main disadvantage of restriction 
fragment end labeling is that there are too many fragments in the high molecular weight range. A polyacrylamide gel can resolve 30 restriction fragment end labeling fragments in the range from 100 to $400 \mathrm{bp}$, but the fragments above this size range are too close together for analysis (22).

Of the two most commonly used electrophoresis gel materials, polyacrylamide is suitable for analysis of low molecular weight fragments (20-1000 bp), while agarose is better for the analysis of high molecular weight fragments (1-20 kb). In gel electrophoresis, migration distance is a nonlinear function of molecular size. The consequence of this is that, when a mixture containing equal numbers of fragments distributed over a wide range of sizes is separated by this technique, the distance between shorter fragments is greater than the distance between longer fragments. Longer fragments tend to overlap under conditions that give quite satisfactory separation of smaller fragments.

This limitation can be overcome by progressively removing high molecular weight fragments until there is equal band spacing over the entire length of the gel. Here we report the development of a subtraction protocol that increases the number of detectable bands on a single DNA fingerprint and its ability to discriminate between closely related bacterial isolates.

\section{MATERIALS AND METHODS}

\section{Overview of the Subtracted Restric- tion Fingerprinting Technique}

Subtracted restriction fingerprinting (SRF) is based on restriction fragment end labeling followed by selective capture and removal of biotin-tagged DNA fragments by streptavidin-coated magnetic particles (Figure 1). The number and size distribution of fragments are determined by the choice of two restriction enzymes used to digest the bacterial DNA. Three types of fragments result from the double digestion: $(i)$ those produced by two cuts of the "detection" enzyme, (ii) those produced by two cuts of the "subtraction" enzyme, and (iii) those produced with one cut by the de- tection and one cut by the subtraction enzyme. Enzymes are selected to produce distinctive $5^{\prime}$ overhangs that can be subsequently filled by Klenow enzyme. EcoRI, for example, produces a four-base overhang with the sequence TTAA, while $M l u$ I produces a four-base overhang with the sequence GCGC. Using this combination of enzymes, type A fragments have TTAA overhangs, type B fragments have GCGC overhangs, and type $\mathrm{C}$ fragments have a TTAA overhang at one end and a GCGC overhang at the other end.

After restriction digestion is completed, Klenow enzyme is added along with digoxigenin-tagged dUTP, biotintagged dCTP, and unlabeled dATP and
dGTP to complete the filling reaction. Type $\mathrm{B}$ and $\mathrm{C}$ fragments (having at least one end with a GCGC overhang) incorporate biotinylated $\mathrm{dCTP}$ and are subsequently removed with streptavidin-coated magnetic particles or columns. Type A fragments do not incorporate biotin but instead have both ends tagged with digoxigenin. These remain in the supernatant after streptavidin subtraction. In the simplest application of SRF, these fragments are separated by agarose gel electrophoresis and, after transfer to a nylon membrane, are visualized by a commercial kit for immunochemical detection based on an anti-digoxigenin antibody conjugated to alkaline phosphatase.

Bacterial chromosomal DNA

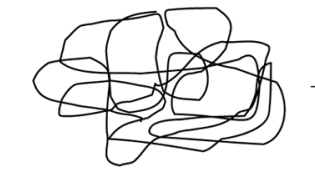

Restriction enzyme producing 5“TTAA overhangs Restriction enzyme producing 5' GCGC overhangs
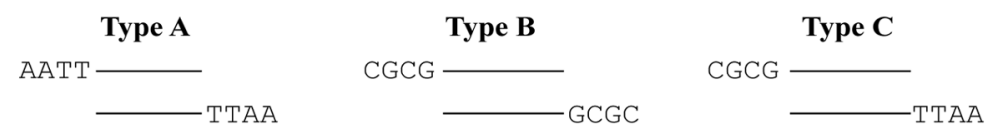

fill-in reaction of 3 'recessed ends with Dig-dUTP, Bio-dCTP, dATP, dGTP

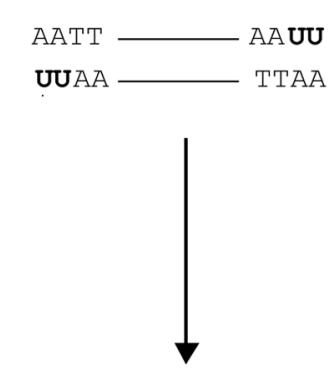

Electrophoresis and detection of digoxigenin-tagged fragments
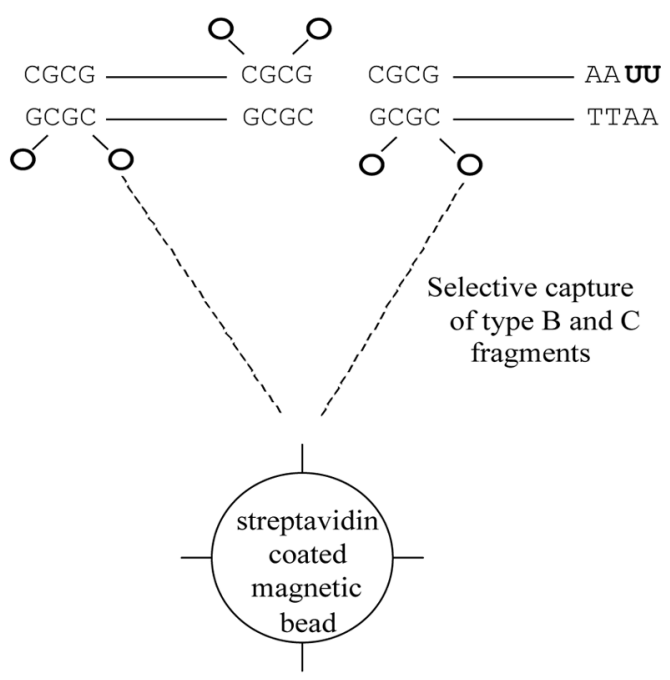

Figure 1. Outline of the main steps of the SRF method. Double digestion of bacterial chromosomal DNA with restriction enzymes producing TTAA and GCGC $5^{\prime}$ overhangs results in type A, B, and C fragments. Generated 3'-recessed ends are filled-in with Klenow enzyme with Bio-dCTP and Dig-dUTP for capture with streptavidin-coated magnetic particles and fragment detection, respectively. 


\section{Bacterial DNA Samples}

Bacterial DNA was extracted from three isolates of Salmonella enterica subsp. enterica serovar Dublin $[(S$. $)$ Dublin] and three laboratory E. coli strains (DH5 $\alpha$, JM110, and JM2163) by the standard lysozyme-phenol procedure for Gram-negative bacteria. Single colonies were inoculated into $5 \mathrm{~mL} \mathrm{LB}$ medium (16) and grown overnight at $37^{\circ} \mathrm{C}$. The bacteria were pelleted by centrifugation for $15 \mathrm{~min}$ at $7000 \times g$ at $4^{\circ} \mathrm{C}$, resuspended in $2 \mathrm{~mL}$ TES buffer (10 mM Tris- $\mathrm{HCl}, \mathrm{pH}$ 8.0, $1 \mathrm{mM}$ EDTA, $100 \mathrm{mM} \mathrm{NaCl}$ ), and centrifuged again for $15 \mathrm{~min}$. The pellet was then resuspended in $500 \mu \mathrm{L}$ TES buffer and, after the addition of $20 \mu \mathrm{L}$ aqueous lysozyme solution (100 mg/mL; Sigma, Deisenhofen, Germany), was incubated for $40 \mathrm{~min}$ at $37^{\circ} \mathrm{C}$. Subsequently, 20 $\mu \mathrm{L}$ of an aqueous solution of $10 \%$ SDS were added. After $10 \mathrm{~min}$ at room temperature, the DNA was extracted twice with phenol:chloroform:pentanol (25:24:1; Roth, Karlsruhe, Germany) and twice with chloroform:pentanol (24:1; Roth). The DNA was then precipitated from the supernatant by the addition of an equal volume of isopropanol (Roth). After centrifugation for $20 \mathrm{~min}$ at $13000 \times \mathrm{g}$, the cleared supernatant was carefully removed, and the DNA pellet remaining was briefly dried and then resuspended overnight at $4^{\circ} \mathrm{C}$ in $50 \mu \mathrm{L}$ double-distilled water. An aliquot was checked for degradation by agarose gel electrophoresis.

\section{Selection of Potential SRF Enzyme Pairs}

Our approach was to settle on EcoRI as the enzyme of choice for $5^{\prime}$ TTAA overhang production-it is neither a rare cutter nor a frequent cutter. With that decision fixed, it was then only necessary to find a suitable partner enzyme-a frequent cutter that would produce a $5^{\prime} \mathrm{G} / \mathrm{C}$ containing overhang. A list of such enzymes was found by going to (http://rebase.neb.com/rebase/ rebase.charts.html) and selecting "enzymes producing $5^{\prime}$ overhangs". We limited our search to those producing four $\mathrm{C} / \mathrm{G}$ nucleotide overhangs (AgeI, BetI, BspMII, Cfr10I, Eco56I, SgrAI, Sse232I, XmaI, AscI, BsePI, MluI, and
SelI). Cutting frequency tables can be found in the online catalog of New England Biolabs (www.neb.com) and then going to "Online Technical Literature, Genomic Analysis" and clicking on the hypertext in the sentence "Summarized in this table are predicted average fragment sizes generated by commonly used restriction enzymes in various genomes". One procedure was to search through a sequence file with the recognition sequence for a selected enzyme using a word processor and counting hits. An alternative method for selecting potential partner enzymes was: $(i)$ use Internet browser to connect to the NEBcutter (http://tools.neb.com/ NEBcutter); (ii) insert sequence data from the bacterial genome of interest into the cutting window (limit is $200 \mathrm{~kb}$ ); (iii) click on "Submit" and select the feature "Custom Digest" to allow the testing of a subset of candidate enzymes; (iv) select enzymes to test; and ( $v$ ) click on "Digest". The results of the test are shown in two forms; we found the "Alternative display" was the most useful for this purpose. In testing the candidate enzyme pairs, we actually used isoschizomers of the above enzymes ( $P a u \mathrm{I}$ is the isoschizomer of BsePI and gave satisfactory results for Salmonella.

\section{Restriction Enzyme Digestion}

We used EcoRI (New England Biolabs GmbH, Frankfurt, Germany) as the detection enzyme (produces TTAA overhangs and an average fragment size of $7 \mathrm{~kb}$ in the E. coli genome). Various subtraction enzymes (produce GCGC overhangs and cut more frequently) were MluI, PauI, and Cfr10I (MBI Fermentas, St. Leon-Rot, Germany), which give average fragment sizes of 4000 , 2000 , and $800 \mathrm{bp}$, respectively, in the $E$. coli genome. In a typical reaction, 100-500 ng genomic DNA are digested with $4 \mathrm{U}$ EcoRI and $5 \mathrm{U}$ of one of the subtraction enzymes and incubated at $37^{\circ} \mathrm{C}$ for $2 \mathrm{~h}$ in $30 \mu \mathrm{L}$ total volume with the restriction buffer (NE buffer) 3 (New England Biolabs GmbH).

\section{Filling Reaction}

The recessed ends remaining after restriction enzyme digestion were filled in either with Klenow enzyme (New
England Biolabs GmbH or MBI Fermentas) or T4 DNA polymerase (MBI Fermentas). For filling in the recessed ends, $2 \mu \mathrm{L}$ dNTP mixture were added directly to a tube containing $30 \mu \mathrm{L}$ restriction enzyme digest to give $40 \mu \mathrm{M}$ dATP, $40 \mu \mathrm{M}$ dGTP, $2 \mu \mathrm{M}$ Dig-dUTP, and $2 \mu \mathrm{M}$ Bio-dCTP. At this point, 0.2 $\mu \mathrm{L}$ Klenow enzyme $(0.4 \mathrm{U})$ was added, and the reaction was allowed to proceed for $10 \mathrm{~min}$ at room temperature.

The unincorporated dNTPs were removed with spin columns (Quantum PREP ${ }^{\circledR}$ PCR Kleen Spin Columns; Bio-Rad Laboratories GmbH, Munich, Germany) by centrifugation at $1000 \times g$ for $2 \mathrm{~min}$ at room temperature. Columns can be reused by washing and refilling with $800 \mu \mathrm{L}$ prehydrated Sephadex ${ }^{\circledR}$ G-50 (Amersham Biosciences, Freiburg, Germany) using $800 \mu \mathrm{L}$ matrix per column.

\section{Streptavidin Capture of Restriction Fragments}

Before use, magnetic particles (Roche Applied Science, Mannheim, Germany) were washed twice in highsalt capture solution ( $2 \mathrm{M} \mathrm{NaCl}, 20$ $\mathrm{mM}$ Tris, and $2 \mathrm{mM}$ EDTA) at a ratio of 1 volume of particles to 6 volumes of capture solution to remove sodium azide. After the second wash, the particles were resuspended in fresh capture solution at a final ratio of 1:6.

An equal volume of the prewashed magnetic particles (approximately 33 $\mu \mathrm{L}$ containing $50 \mu \mathrm{g}$ ) was added to each tube of desalted filled restriction fragments. The tubes were incubated for $2 \mathrm{~h}$ at room temperature with continuous rotation to keep the particles in suspension. Separation was performed in a magnetic rack (Dynal MPC-P-12; Dynal $\mathrm{GmbH}$, Hamburg, Germany) that held the biotinylated DNA fragments against one side of each tube. The resultant suspensions of purified type A fragments were transferred with a micropipet to spin columns for a second desalting step (as described above), then placed in a vacuum concentrator, and reduced from approximately $66 \mu \mathrm{L}$ to $10 \mu \mathrm{L}$ so that the samples would fit into the wells of the agarose gel.

For comparison, we also performed the capture of restriction products with

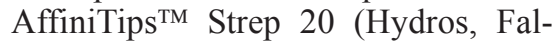


mouth, MA, USA). These are pipet tip columns containing recombinant streptavidin covalently coupled to a porous element within the tip. These fit onto a standard micropipet, and each sample is simply pipetted up and down for 2-3 min to achieve complete removal of biotin labeled fragments.

\section{Electrophoretic Separation of the Restriction Fragments}

In most cases, samples were run on $20-\mathrm{cm} 1.2 \%$ agarose gels at $100 \mathrm{~V}$ for 16 h. For higher resolution for (S.) Dublin isolates, a $30-\mathrm{cm}$ agarose gel was used. Once electrophoresis was completed, the gel was treated by alkaline solution containing $1 \mathrm{M} \mathrm{NaCl}$ and $0.5 \mathrm{M} \mathrm{NaOH}$ to denature DNA fragments and then neutralized with $1 \mathrm{M} \mathrm{NaCl}, 0.5 \mathrm{M}$ Tris, $\mathrm{pH} 7.5$, for $30-40 \mathrm{~min}$.

\section{Detection of the Separated Restriction Fragments}

Transfer of DNA fragments from the gel to a nylon support (Hybond ${ }^{\mathrm{TM}}-\mathrm{N}+$; Amersham Biosciences) required $1 \mathrm{~h}$

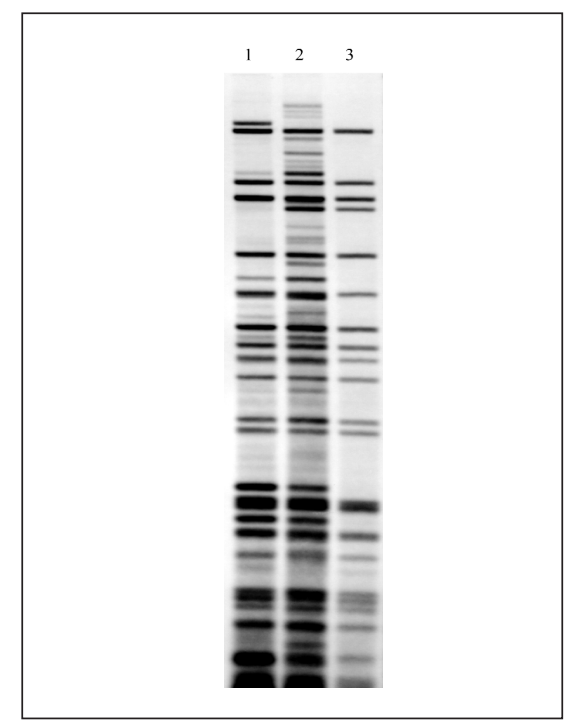

Figure 2. Effect of the amount of DNA on the efficiency of capture with streptavidin-coated matrices. Different amounts ( 1 and $1.5 \mu \mathrm{g})$ of $E$. coli DNA were digested, filled-in, and captured with magnetic particles or Affini-Tip columns. Lane 1, capture with Affini-Tip columns using $0.1 \mathrm{M} \mathrm{NaCl}$ low-salt buffer and $1.5 \mu \mathrm{g}$ DNA of DH5 $\alpha$ strain; lane 2, capture with $1.5 \mu \mathrm{g} \mathrm{E}$. coli DNA (JM110 strain) using $1 \mathrm{M} \mathrm{NaCl}$ high-salt buffer and magnetic particles; lane 3, capture with $1 \mu \mathrm{g} E$. coli (JM110 strain) in the same highsalt buffer with magnetic particles. using $10 \times \mathrm{SSC}$ and a PosiBlot ${ }^{\mathrm{TM}}$ Pressure Blotter (Stratagene Europe, Amsterdam, The Netherlands). After transfer, DNA was immobilized on the filter by UV treatment $\left(120 \mathrm{~mJ} / \mathrm{cm}^{2}\right)$ using a Stratalinker ${ }^{\mathrm{TM}}$ (Stratagene Europe). Detection of digoxigenin-labeled DNA on the filter was performed according to the manufacturer's instructions (Roche Applied Science). Briefly, the filter was preincubated for $30 \mathrm{~min}$ in blocking solution $(0.1 \mathrm{M}$ maleic acid, $0.15 \mathrm{M}$ $\mathrm{NaCl}, 1 \times$ Roche blocking reagent, $\mathrm{pH}$ 7.5) and then treated with an alkaline phosphatase-conjugated antibody against digoxigenin diluted 1:5000 in blocking solution. Unbound antibody was removed by $2 \times 15 \mathrm{~min}$ washes with maleic acid buffer. After a short equilibration in alkaline buffer $(0.1 \mathrm{M}$ Tris, $\mathrm{pH}$ 9.5, 0.1 M NaCl), the filter was sealed in a plastic bag containing developing solution consisting of two chromogenic substrates for alkaline phosphatase NBT and BCIP in alkaline buffer. Development was occasionally checked visually but was usually completed within $16 \mathrm{~h}$. Images were captured with a CCD camera and saved as TIFF files for further evaluation.

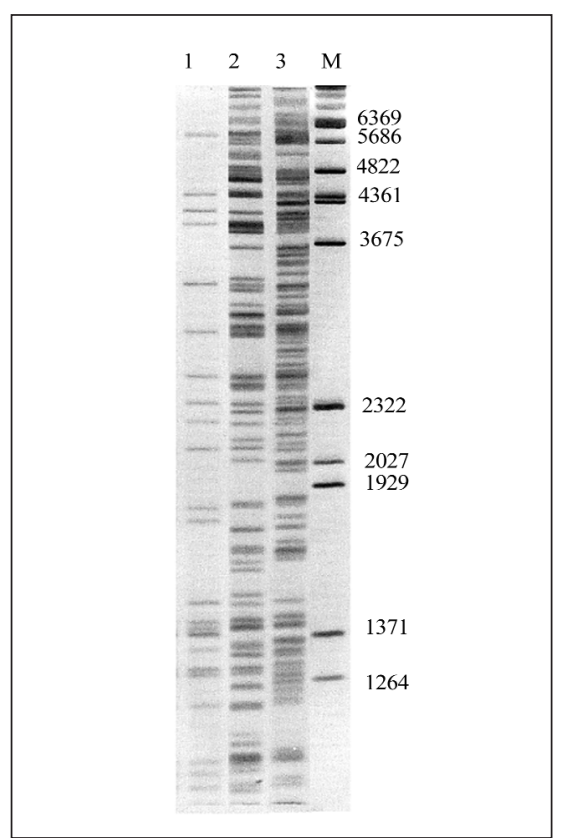

Figure 3. Banding patterns obtained with $E$. coli DNA strain JM2163 and different combinations of restriction enzymes. $M$, molecular size marker ( $\lambda$ DNA-HindIII and BstEII digested, Dig-dUTP filled). Lane 1, pattern with EcoRI + Cfr10I; lane 2, pattern with EcoRI + PauI; lane 3, pattern with EcoRI $+M l u \mathrm{I}$. 


\section{Research Report}

\section{RESULTS}

\section{Capture Efficiency}

Complete capture and removal of unwanted fragments are essential to the method. With $50 \mu \mathrm{g}$ streptavidin-coated magnetic particles, the maximum amount of captured biotinylated DNA achieved with high-salt capture buffer (containing $1 \mathrm{M} \mathrm{NaCl}$ ) was in the order of $1 \mu \mathrm{g}$, as shown in Figure 2. The result obtained with $1 \mu \mathrm{g}$ biotinylated DNA is shown in Figure 2, lane 3, while the result obtained with $1.5 \mu \mathrm{g}$ biotinylated DNA is shown in lane 2. This was in good agreement with the manufacturer's estimate that $1 \mathrm{mg}$ of magnetic particles can bind $10 \mathrm{pmol}$ of a $1.5-\mathrm{kb}$ DNA fragment containing a single biotin-labeled end. In the first case, the result was a relatively clean filter with discrete, strong bands representing the small remaining population of DNA fragments - those without a biotin subtraction tag. In the overloaded system, shown in Figure 2, lane 2 , some of biotin-tagged fragments escaped capture and appeared as additional weak bands on the filter. A similar result (not shown) was obtained with $1 \mu \mathrm{g}$ DNA when the concentration of sodium chloride was reduced to 0.1 $\mathrm{M}$, demonstrating that high-salt buffer was necessary.

The Affini-Tip streptavidin pipet-tip columns were more efficient than magnetic particles. With the high-salt (1 M $\mathrm{NaCl}$ ) capture buffer used for magnetic particle capture, Affini-Tip columns could remove $1.5 \mu \mathrm{g}$ biotinylated DNA fragments. In low-salt $(0.1 \mathrm{M} \mathrm{NaCl})$ buffer, it was possible to subtract $1 \mu \mathrm{g}$ biotinylated DNA, but some background appeared with $1.5 \mu \mathrm{g}$ DNA (Figure 2, lane 1); however, this was no advantage in practice, as a desalting step was required with either buffer.

With either method, it was necessary to remove salt after the subtraction step before electrophoresis. The $0.1 \mathrm{M}$ $\mathrm{NaCl}$, which was sufficient for subtraction with Affini-Tip columns, required a desalting step because it was necessary to reduce the sample volume by evaporation before loading onto the gel. Complete removal of biotin-agged fragments with Affini-Tip columns required only a few minutes of pipetting in contrast to the $2 \mathrm{~h}$ needed for magnetic particle capture.

The amount of chromosomal DNA required for a strong fingerprint image ranged from 100 to $500 \mathrm{ng}$ total DNA, so the routine capture protocol based on $50 \mu \mathrm{g}$ of magnetic particles and a high-salt capture buffer ensured at least 2-fold excess in absorption capacity.

Without capture, double digestion of $1 \mu \mathrm{g} E$. coli genomic DNA with the combination of EcoRI and Cfr 10I produced so many fragments that only a smear could be seen after electrophoresis (not shown).

\section{Restriction Enzyme Combinations}

EcoRI was selected as the TTAAproducing detection enzyme. It gave an average fragment length with $E$. coli genomic DNA of $7 \mathrm{~kb}$, which was suitable for analysis with the present agarose gel electrophoresis system.

The three subtraction enzymes tested-MluI, PauI, and Cfr10I-cut at an average frequency of 4000, 2000, and $800 \mathrm{bp}$, respectively, in E. coli. As shown in Figure 3, there is a progressive decline in the number of detected fragments after magnetic bead capture when the subtraction enzyme cuts more frequently. The use of MluI gave about 65 bands, PauI produced about 45 bands, and Cfr10I produced about 22 in the size range from 1264 to $6369 \mathrm{bp}$ (Figure 3, lanes 3, 2, and 1, respectively).

For typing $E$. coli using EcoRI as the detection enzyme, the best subtraction enzyme for a $20-\mathrm{cm}$ agarose gel was $C f r 10 \mathrm{I}$. While it might seem an advantage to use $M l u I$ because with 65 bands it could give greater discrimination power, Figure 3, lane 3, shows that it would be difficult to resolve that number of bands using a $20-\mathrm{cm}$ agarose gel. The EcoRI + PauI combination (Figure 3, lane 2) produced an intermediate number of bands that could be resolved with conventional image analysis programs, although some overlap between bands is apparent. The EcoRI + Cfr $10 \mathrm{I}$ combination (Figure 3, lane 1) gives the clearest picture, which ensures high reproducibility.

\section{The Banding Pattern in Different Bacterial Species}

Since restriction enzymes are considered to be a bacterial defense against foreign DNA, they must discriminate between self and foreign DNA and therefore are a characteristic of each type of bacteria. One would expect that the number of restriction sites for a given enzyme depends on the bacterial genome under investigation. Figure 4 shows banding patterns obtained with $E c o$ RI $+C f r 10$ I restriction enzymes on three laboratory $E$. coli strains (DH5 $\alpha$, JM110, and JM2163) and on two isolates of (S.) Dublin. Fewer bands were detected with $(S$.) Dublin than with $E$. coli, with this restriction enzyme combination confirming that there is an interspecies difference in the restriction fragments. Only $10-12$ bands are detected in Salmonella strains (Figure 4A, lanes 3 and 4), and this is insufficient for typing. Even without capture (Figure 4A, lanes

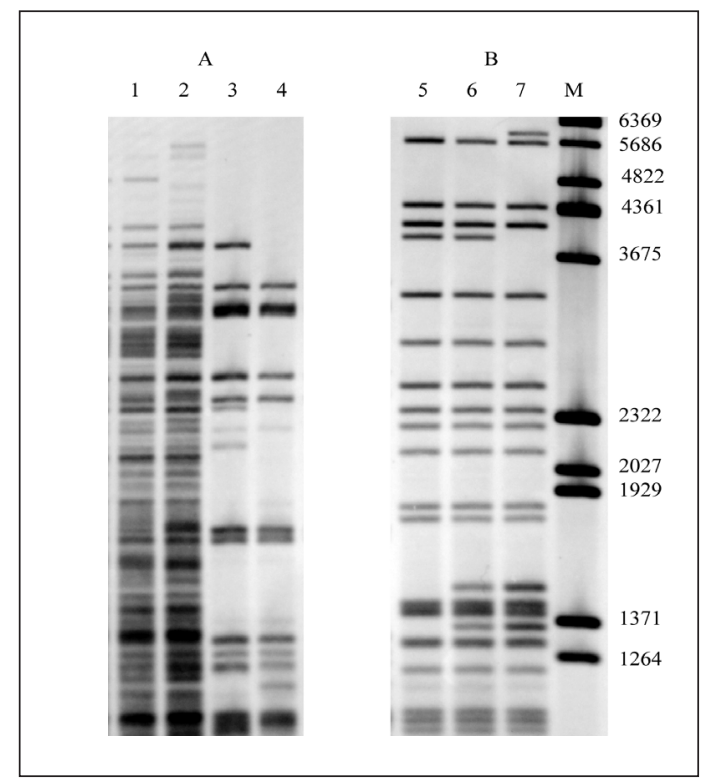

Figure 4. Banding patterns obtained by SRF with $E$. col and Salmonella DNA digested with EcoRI $+C f r 10 \mathrm{I}$ restriction enzymes. $M$, molecular size marker ( $\lambda$ DNA-HindIII and BstEII digested, Dig-dUTP filled). (A) Two Salmonella strains. Lanes 1 and 2, double digested without magnetic bead capture; lanes 3 and 4, the same Salmonella strains, double digested with magnetic bead capture. (B) Three E. coli strains, JM110, JM2163, and DH5 $\alpha$. Lanes 5, 6, and 7, double digested with $E c o$ RI $+C f r 10$ I with magnetic bead capture. 
1 and 2), there are fewer bands from Salmonella than E. coli. To discriminate between Salmonella strains, it is necessary to use a subtraction enzymes such as PauI, which is less stringent, allowing more fragments to escape capture.

For analysis of (S.) Dublin, EcoRI + $P a u$ I was the best combination and resulted in approximately 50 well-resolved bands, which was excellent for differentiating various bacterial isolates (Figure 5). In this case, a longer 30-cm agarose gel was used to increase discriminating power (a function of the number of bands) without sacrificing reproducibility (a function of the strength of the bands and the spacing between them).

\section{DISCUSSION}

Genomic polymorphism within bacteria species is the molecular basis for genomic typing. Typing methods are important for detection of new mutations in strains intended for immunization, for the detection of hypermutable strains such as those found among pathogenic E. coli and Salmonella Spp. (9), and for epidemiological studies where previously unidentified strains may be encountered.

Some typing methods require sequence information for the regions to be analyzed so that, for example, PCR primers or hybridization probes can be synthesized. This is true for some forms of microarray analysis based on oligonucleotide synthesis or immobilization and is true for SNP analysis in which regions containing a polymorphism must be amplified. In some instances, however, it is an advantage to have a method that can detect unanticipated alterations to the genome. One advantage of RFLP-based methods (pulsed-field gel electrophoresis, re- striction fragment end labeling, and AFLP) is that they do not depend on the prior knowledge of target sequences and can thus detect sequence variations in "anonymous" DNA. These anonymous DNA typing methods essentially reveal SNPs because restriction enzyme cutting is blocked by a singlebase sequence change.

When rare cutting enzymes are used on a bacterial genome such as (S.) Dublin, only a limited number of large fragments is produced, and pulsed-field gel electrophoresis can reveal all or most of them. It is difficult to resolve a large number of fragments by conventional pulsed-field gel electrophoresis because band overlapping becomes a problem. Restriction fragment end labeling is a method by which all restriction fragments are end-labeled for detection, but, because of the limitations of gel electrophoresis, only a fraction of these bands can be resolved at the 
low molecular weight range. Fragments longer than $400 \mathrm{bp}$ tend to be crowded and cannot be resolved (22). AFLP uses selective primers to amplify a subset of restriction fragments for detection. The gels used for restriction fragment end labeling and AFLP can resolve more bands than is possible with pulsed-field gel electrophoresis, but band distribution is not optimized.

With SRF, the total number of restriction fragments is substantially reduced so that there is generally more space between bands, but, more importantly, a greater proportion of larger fragments are removed than smaller fragments. This bias in removing the larger bands has the effect of giving equal band spacing over the entire length of a standard electrophoresis gel and maximizes the information content of the gel (Figure 5). Theoretically, when the number of informative bands is increased, the discrimination power of the analytical method increases. The number of resolved bands with SRF is similar to that obtained by the AFLP method that is based on PCR, ligation, and high-resolution polyacrylamide gel separation. Our first experiments showed that the SRF technique could be used not only with agarose gels but also with high-resolution polyacrylamide gels to produce hundreds of well-resolved bands. The number of detected bands is limited only by the resolution of the gel system and can be adjusted by choosing new combinations of restriction enzymes.

The size and number of fragments left in solution after the capture step of SRF is determined by the cutting frequency of both restriction enzymes used. It is clear that if the detection enzyme producing $5^{\prime}$ TTAA overhangs cuts more frequently, then the general size and number of detected fragments will be higher. On the contrary, if the subtraction enzyme producing $5^{\prime}$ GCGC overhangs is a more frequent cutter, then the average fragment size will also be smaller, but the number of bands is reduced. Fewer bands remain when the GCGC-producing subtraction enzyme cuts more frequently. One biotin-labeled $\mathrm{dCTP}$ incorporated in the filling reaction is sufficient for removal by the streptavidin-coated magnetic particles. More and more bands have at least one
5' GCGC overhang and will be captured when the subtraction enzyme cuts more frequently. The choice of the detection enzyme is determined as follows. It should cut bacterial DNA every 5-10 $\mathrm{kb}$. Taking into consideration the size of the $E$. coli genome $\left(4.6 \times 10^{6} \mathrm{bp}\right)$ and EcoRI enzyme cutting frequency of every $7 \mathrm{~kb}$, the calculated number of fragments is about 660. The subtraction enzyme that cuts more frequently removes most of the fragments. For example, in Figure 3, the effects of $M l u \mathrm{I}$, PauI, and Cfr $10 \mathrm{I}$ on the number of detected bands are shown. Enzyme MluI cuts $E$. coli DNA every $4 \mathrm{~kb}$, with $2 \mathrm{~kb}$ for PauI and $800 \mathrm{bp}$ for $C f r 10 \mathrm{I}$. The total number of fragments in a restriction digest is increased, but there is a progressive majority of fragments with $5^{\prime}$ GCGC overhangs. This results in fewer and fewer bands detected (Figure 3).

Each electrophoretic separation system (agarose vs. polyacrylamide gels; capillary electrophoresis, conventional horizontal slab gel electrophoresis, or verticle "sequencing" electrophoresis) has inherent limits with respect to resolution and fragment size range, so, to maximize information content, it is desirable to select an optimal pair of SRF enzymes for the system being used. With the conventional agarose gel and the $E$. coli genome, the best choice is EcoRI + Cfr10I, while, for Salmonella, the best choice is EcoRI + PauI. These combinations give a range of well-separated fragments from 1 to $6 \mathrm{~kb}$ (Figures 3, 4, and 5). Other candidate TA overhang-producing detection enzymes (AseI, NdeI, VspI, ApoI, and MfeI) were not needed for the E. coli or (S.) Dublin genomes but would be valuable tools for other bacterial genomes. The number of restriction fragments is not the only consideration when choosing an SRF enzyme pair. The enzyme pair that we tested $(E c o \mathrm{RI} / P a u \mathrm{I})$ produced a more variable banding pattern (higher discrimination) in one strain of Salmonella than another, so it is useful to test several combinations and select the one that produces the highest discriminatory index for the strains or isolates under analysis.

To use the method in epidemiological investigations, it would be necessary to have tests extensively performed by many research groups using reference strains and various sources of reagents.

In conclusion, SRF represents a significant improvement over other methods for genomic typing of bacteria. Future improvements to SRF will be directed to reduce the time of analysis from two days to one day. Agarose gel electrophoresis requires $16 \mathrm{~h}$, but highvoltage polyacrylamide electrophoresis can reduce this to 3-4 h. However, the greatest improvement in speed will come from reducing the time for analysis. One means of accomplishing this would be to use direct silver staining of the polyacrylamide gel. This would reduce the detection time from overnight to $90 \mathrm{~min}$. Alternatively, fluorescently labeled fragments can be detected within 20 min using fluorescent scanners such as Typhoon ${ }^{\mathrm{TM}}$ or FluorImager ${ }^{\mathrm{TM}}$ (both from Amersham Biosciences) with sensitivity approaching $10 \mathrm{pg} /$ band. Capillary electrophoresis could also reduce the time of analysis to less than an hour $(10,19)$.

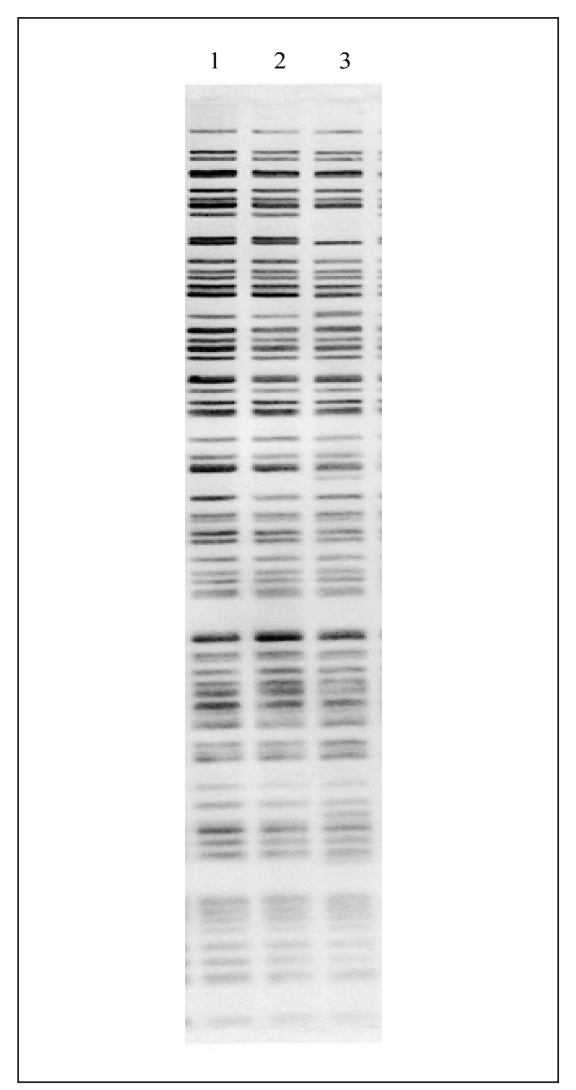

Figure 5. Banding patterns obtained by SRF with three $(S$.) Dublin isolates using a $30-\mathbf{c m}$ agarose gel and $E c o R I+P a u I$ double digestion. Lanes 1 and 2, identical patterns; lane 3 , closely related but genetically different isolate. 


\section{ACKNOWLEDGMENTS}

The authors thank Steve Boyd from Hydros for providing us with trial samples of Affini-Tips columns. Special thanks to Dieter Bunke for processing images for publication. This study was supported by DFG grant no. 436 RUS 113/585/1-1 to J.C. and H.N.

\section{REFERENCES}

1.Coenye T., T. Spilker, A. Martin, and J.J. LiPuma. 2002. Comparative assessment of genotyping methods for epidemiologic Study of Burkholderia cepacia Genomovar III. J. Clin. Microbiol. 40:3300-3307.

2.Grimont, F. and P.A.D. Grimont. 1986. Ribosomal ribonucleic acid gene restriction patterns as potential taxonomic tools. Ann. Inst. Pasteur Microbiol. 137:165-175.

3.Hermans, P.W., M. Sluijter, T. Hoogenboezem, H. Heersma, A. van Belkum, and R. de Groot. 1995. Comparative study of five different DNA fingerprint techniques for molecular typing of Streptococcus pneumoniae strains. J. Clin. Microbiol. 33:1606-1612.

4.Inglis, T.J.J., L. O'Reilly, N. Foster, A. Clair, and J. Sampson. 2002. Comparison of rapid, automated ribotyping and DNA macrorestriction analysis of Burkholderia pseudomallei. J. Clin. Microbiol. 40:3198-3203.

5.Janssen, P., R. Coopman, G. Huys, J. Swings, M. Bleeker, P. Vos, M. Zabeau, and K. Kersters. 1996. Evaluation of the DNA fingerprinting method AFLP as a new tool in bacterial taxonomy. Microbiology 142:18811893.

6.Jonas, D., H.G. Meyer, P. Matthes, D. Hartung, B. Jahn, F.D. Daschner, and B. Jansen. 2000. Comparative evaluation of three different genotyping methods for investigation of nosocomial outbreaks of Legionnares' disease in hospitals. J. Clin. Microbiol. 38:2284-2291.

7.Kotetishvili, M., O.C. Stine, A. Kreger, J.G. Morris, Jr., and A. Sulakvelidze. 2002. Multilocus sequence typing for characterization of clinical and environmental Salmonella strains. J. Clin. Microbiol. 40:1626-1635.

8.Kremer, K., D. van Soolingen, R. Frothingham, W.H. Haas, P.W.M. Hermans, C. Martin, P. Palittapongarnpim, B.B. Plikaytis, et al. 1999. Comparison of methods based on different molecular epidemiological markers for typing of Mycobacterium tuberculosis complex strains: interlaboratory study of discriminatory power and reproducibility. J. Clin. Microbiol. 37:2607-2618.

9.LeClerc, J.E., B. Li, W.L. Payne, and T.A. Cebula. 1996. High mutation frequencies among Escherichia coli and Salmonella pathogens. Science 274:1208-1211.

10.Legendre, B.L., Jr., D.L. Moberg, D.C. Williams, and S.A. Soper. 1997. Ultrasensitive near-infrared laser-induced fluorescence detection in capillary electrophoresis using a diode laser and analanche photodiode. J. Chromatogr. 779:185-194.
11.Liebana, E., L. Garcia-Migura, M.F. Breslin, R.H. Davies, and M.J. Woodward. 2001. Diversity of strains of Salmonella enter ica serotype enteritidis from English poultry farms assessed by multiple genetic fingerprinting. J. Clin. Microbiol. 39:154-161.

12.Liebisch, B. and S. Schwarz. 1996. Evaluation and comparison of molecular techniques for epidemiological typing of Salmonella enterica subsp. enterica Serovar dublin. J. Clin. Microbiol. 34:641-646.

13.Nair, S., E. Schreiber, K.L. Thong, T. Pang, and M. Altwegg. 2000. Genotypic characterization of Salmonella typhi by amplified fragment length polymorphism fingerprinting provides increased discrimination as compared to pulsed-field gel electrophoresis and ribotyping. J. Microbiol. Methods 41:35-43.

14.Olsen, J.E. 1990. An improved method for rapid isolation of plasmid DNA from wild type Gram-negative bacteria for plasmid restriction profile analysis. Lett. Appl. Microbiol. 10:209-212.

15.On, S.L. and C.S. Harrington. 2000. Identification of taxonomic and epidemiological relationships among Campylobacter species by numerical analysis of AFLP profiles. FEMS Microbiol Lett. 193:161-169.

16.Sambrook, J., E.F. Fritsch, and T. Maniatis. 1989. Molecular Cloning: A Laboratory Manual, 2nd ed. Appendix A. CSH Laboratory Press, Cold Spring Harbor, NY.

17.Schwartz, D.C. and C.R. Cantor. 1984. Separation of yeast chromosome-sized DNAs by pulsed field gradient gel electrophoresis. Cell 37:67-75.

18.Scott, F., J. Threlfall, and C. Arnold. 2002 Genetic structure of Salmonella revealed by fragment analysis. Int. J. Syst. Evol. Microbiol. 52:1701-1713

19.Skeidsvoll, J. and P.M. Ueland. 1995 Analysis of double-stranded DNA by capillary electrophoresis with laser-induced fluorescence detection using the monomeric dye SYBR Green I. Anal. Biochem. 231:359-365.

20.van Doorn, N.E., F. Namavar, J.G. Kusters, E.P. van Rees, E.J. Kuipers, and J. de Graaff. 1998. Genomic DNA fingerprinting of clinical isolates of Helicobacter pylori by REP-PCR and restriction fragment end-labelling. FEMS Microbiol Lett. 160:145-150.

21.van Eldere, J., P. Janssen, A. HoefnagelsSchuermans, S. van Lierde, and W.E. Peetermans. 1999. Amplified-fragment length polymorphism analysis for molecular typing of Streptococcus pneumoniae isolates. J. Clin. Microbiol. 37:2053-2057.

22.van Steenbergen, T.J.M., S.D. Colloms, P.W.M. Hermans, J. de Graaf, and R.H.A. Plasterk. 1995. Genomic DNA fingerprinting by restriction fragment end labelling. Proc. Natl. Acad. Sci. USA 92:5572-5576.

23.Tenover, F.C., R.D. Arbeit, R.V. Goering, P.A. Mickelsen, B.E. Murray, D.H. Persing, and B. Swaminathan. 1995. Interpreting chromosomal DNA restriction patterns produced by pulsed-field gel electrophoresis: criteria for bacterial strain typing. J. Clin. Microbiol. 33:2233-2239.

24.Weide-Botjes, M., B. Kobe, C. Lange, and S. Schwarz. 1998. Molecular typing of Sal monella enterica serovar Hadar: evaluation and application of different typing methods. Vet. Microbiol. 61:215-227.

25.Welsh, J. and M. McClelland. 1990. Fingerprinting genomes using PCR with arbitrary primers. Nucleic Acids Res. 18:7213-7218.

26.Zhao, S., S.E. Mitchell, J. Meng, S. Kresovich, M.P. Doyle, R.E. Dean, A.M. Casa, and J.W. Weller. 2000. Genomic typing of Escherichia coli $\mathrm{O} 157: \mathrm{H} 7$ by semi-automated fluorescent AFLP analysis. Microbes Infect. 2:107-113.

Received 25 September 2002; accepted 3 December 2002.

Address correspondence to:

Dr. Heiner Niemann

Institute for Animal Science (FAL)

Department of Biotechnology

Mariensee, 31535 Neustadt, Germany

e-mail:niemann@tzv.fal.de

For reprints of this or any other article, contact Reprints@BioTechniques.com 